\title{
O instituto da desapropriação como meio de efetivação do requisito da função social
}

\author{
DOI: $10.5935 / 2447-8539.201900022$ \\ PAULO ROBERTO OLIVEIRA SANTOS; MATEUS ALVES GONDIM \\ e-mail:paulo.santos@imepac.edu.br
}

\section{Resumo}

A presente pesquisa buscou esclarecer uma das principais ferramentas para o combate à desigualdade social na luta pela justiça social. Com um amplo campo de pesquisa, direcionou-se para realizar um estudo profundo sobre como o direito pode e deve solucionar as questões sociais, dando efetividade aos princípios constitucionais, em especial aqui tratado o requisito da função social da propriedade para fins de interesse social e reforma agrária através do instituto da desapropriação, dentro dos termos da lei e buscando trazer ao mundo dos fatos os anseios constitucionais

Palavras-chave: Desapropriação. Função Social. Princípio.

\section{Abstract}

The present research aimed to clarify one of the main tools to combat social inequality in the struggle for social justice. This work was based on a broad field of research which directed to carry out an in-depth study on how law can and should solve social issues by giving effectiveness to the constitutional principles, especially when dealt with the principle of the social function of property. This principle in question has the purpose of social interest and agrarian reform through the institute of expropriation under the terms of law by seeking to bring to the world of facts the constitutional longings.

Keywords: $\quad$ Expropriation. Social Function. Principles.

\section{INTRODUÇÃO}

A desapropriação por interesse social para fins de reforma agrária é instituto jurídico positivo, ou seja, há previsão legal expressa acerca dele, em especial no artigo 184 na Constituição da República Federativa do Brasil de 1988. Ali se elenca um entendimento de cunho voltado ao interesse social e ao bem-estar das pessoas e esses fundamentos serão apresentados com mais profundidade no decorrer do presente trabalho e os temas pertinentes serão abordados eventualmente.
É importante salientar que as problemáticas sociais constantes devem sempre ser objeto de estudo da Ciência Jurídica; cabe a ela indicar caminhos teóricos e práticos capaz de encontrar soluções satisfatórias e eficazes para toda a sociedade.

A desigualdade social prejudica de maneira ampla e direta a dignidade da pessoa humana; por isso a Constituição traz a noção de "função social da propriedade" como um princípio do direito. Este trabalho busca esclarecer como tal princípio poderá ser efetivado através dessa modalidade de desapropriação.

Ao tratar-se da efetividade do requisito da função social da propriedade expresso no inciso XXIII do artigo $5^{\circ}$ da 
Constituição Federal de 1988 é necessário ter uma noção de como a desapropriação impacta o meio social, valorizando a pessoa humana e sua honra, quando efetuada de maneira adequada e dentro do devido meio e procedimento legais.

Pelo texto constitucional, fica expressa a incumbência do Estado quanto ao instituto da desapropriação. Por isso, não é de se estranhar que o que deve ser argüido é o fato de que esta não se dá conforme prevê a norma no mundo dos fatos, vez que existem várias propriedades que insistem em não cumprir com sua devida função social e ainda assim não são objeto de desapropriação.

\section{Problemas e premissas}

Grandes propriedades rurais no território brasileiro, mesmo não atendendo ao requisito da "devida função social da propriedade", estabelecido na Constituição Federal de 1988, ainda não são objeto da já referida modalidade de desapropriação. Assim, apesar de ser possível verificar-se a existência de propriedades urbanas descumprindo tal requisito, este trabalho se aterá a questões do âmbito das propriedades rurais de grande porte, também conhecidas como latifúndios.

Dentro da visão constitucional, será debatida a possível solução para que o supracitado requisito se torne mais efetivo na prática, tendo como norte a instituto constitucional da desapropriação. Este trabalho, portanto, tem como principal objetivo buscar a solução legal mais plausível para garantir sua efetividade.

O método optado para a pesquisa do presente trabalho é hipotético dedutivo, tendo em vista a premissa geral e dessa partindo para se alcançar a específica. No que toca à metodologia, utilizou-se o recurso de pesquisa bibliográfica fundada na doutrina adequada, fontes de sites especializados para levantamento de dados e estatísticas e em obras clássicas que trazem entendimentos necessários ao desenvolvimento da ideia central.

\section{Contextualização histórica, dos princípios constitucionais, da função social da propriedade e desenvolvimento do estudo}

Para iniciar-se a exposição da tese aqui defendida, é interessante que se possa fazer uma breve análise contextual histórica a respeito do tema "propriedade". Tomando-se como ponto de partida o entendimento do que seria a propriedade e quais os seus limites, é possível reconhecê-lo como objeto de discussão e de mudanças ao longo da história. Nessa perspectiva, vale ressaltar que a Constituição Federal de 1988 consagra em seu artigo 184:
Art. 184. Compete à União desapropriar por interesse social, para fins de reforma agrária, o imóvel rural que não esteja cumprindo sua função social, mediante prévia e justa indenização em títulos da dívida agrária, com cláusula de preservação do valor real, resgatáveis no prazo de até vinte anos, a partir do segundo ano de sua emissão, e cuja utilização será definida em lei.

Contudo, é preciso apontar que o requisito da função social da propriedade foi pela primeira vez mencionado no sistema e ordenamento legal brasileiro na Constituição Federal de 1967. Dado o texto da Emenda Constitucional de $n^{\circ} 1$ de 1969 houve então a inclusão de tal ideia de função social de uma propriedade, sendo cláusula de ordem social e até mesmo econômica, ao mesmo tempo em que coexistia com o conceito de propriedade privado, sem prejuízos recíprocos.

A ideia de dar função ao bem, sendo que neste caso o bem seria a propriedade rural, mas amplamente tratando-se da ideia de "bem", remonta ao jusnaturalismo. Foi discutido por diversas vezes em momentos históricos conforme a sociedade sofria mutações em seus costumes e a tecnologia avançava.

No século XIX, o modelo então vigente de propriedade foi duramente criticado por Karl Marx, filósofo e pensador que atribuía as incoerências do sistema e propunha uma mudança para um mundo mais justo (MARX, 1999). Entretanto, é necessário esclarecer que o Requisito da função social da propriedade, não guarda relação com o comunismo marxista, que oferecia a ideia de expropriação dos meios de produção para a classe operária, mas, o conceito de função social da propriedade apenas sugere que os bens privados sejam utilizados com base no interesse social, mas não extingue a propriedade do dono, sendo que este continua sendo proprietário exclusivo de seus bens.

Assim é que, percebida como fenômeno histórico, as reflexões propostas sobre a propriedade devem ser explicadas da melhor maneira possível, sendo que é preciso explanar o conceito de propriedade, que é entendido como o sendo o direito de gozar, fruir, dispor e reivindicar o bem.

Ainda, é necessário que se entenda que há uma diferença em ser proprietário e ser possuidor. A mera posse não configura propriedade, e no direito brasileiro existem duas teorias que são estudadas, sendo uma a adotada pelo sistema jurídico, não excluindo a importância da outra, vez que é objeto de estudo quando se trata do tema da usucapião.

Mas, antes de continuar, é preciso então entender que a primeira teoria é conhecida como Teoria Subjetiva, também conhecida por Teoria de Savigny. Dentro dessa teoria, entende-se que a posse é formada pelo bem físico, a coisa, também chamada de corpus, e ainda a 
intenção de ser dono, ou seja, a vontade de ser proprietário, chamado de animus domini (DINIZ, 2009).

Já a segunda teoria, que é também a adotada pelo ordenamento jurídico pátrio como regra geral, é a Teoria Objetiva, ou Teoria de Ihering, que traz a noção de que não há a necessidade da intenção de ser dono, ou seja, o animus domini torna-se prescindível, sendo o necessário apenas a conduta do sujeito, que age em face de um bem como se dono fosse.

Sem se distanciar do tema da propriedade, é interessante destacar o que, conforme Silvio Venosa (2008, p. 149), "a história da propriedade é decorrente diretamente de sua organização política".

Com o intuito de iniciar as disposições seguintes, tendo já esclarecido questões referentes à posse e propriedade, e ainda uma rápida contextualização histórica, para um melhor entendimento, em primeiro lugar é preciso se entender que o requisito ora abordado funciona como um princípio norteador do exercício do direito de propriedade. Nesses termos, é forçoso a compreensão do que é um princípio e qual sua conceituação, para tanto, Celso Antônio Bandeira de Mello (1996, p. 545-546) define:

Mandamento nuclear de um sistema,
verdadeiro alicerce dele, disposição
fundamental que se irradia sobre diferentes
normas compondo lhes o espírito e servindo de
critério para sua exata compreensão e
inteligência por definir a lógica e a
racionalidade do sistema normativo, no que lhe
confere tônica e lhe dá sentido harmônico.

O princípio rege de maneira geral um entendimento, uma noção, uma ideia sobre o fato ou o objeto da discussão. Ele norteia as decisões que deverão ser tomadas, pois não é como a lei, positivamente falando, pois abrange casos que nem mesmo foram previstos na lei e, também, casos hipotéticos. São de extrema relevância ao se abordar assuntos como garantias e direitos e estão em patamar de destaque.

Um princípio deve sempre ser levado em conta como crucial em qualquer hermenêutica jurídica. 0 princípio, como bem explica Bandeira de Mello, irradia sobre diversas normas e é critério para sua exata compreensão.

Para tanto, vale entender com mais precisão o requisito da função social da propriedade, para que se possa definir o que é e saber com precisão quem o cumpre ou não, neste contexto é preciso esclarecer, para isso, a Constituição Cidadã novamente traz um entendimento assertivo sobre o tema:

Art. 186. A função social é cumprida quando a propriedade rural atende, simultaneamente, segundo critérios e graus de exigência estabelecidos em lei, aos seguintes requisitos:

I - aproveitamento racional e adequado;
II - utilização adequada dos recursos naturais disponíveis e preservação do meio ambiente;

III - observância das disposições que regulam as relações de trabalho;

IV - exploração que favoreça o bem-estar dos proprietários e dos trabalhadores.

Para tanto, entende-se como cumpridora da devida função social aquela propriedade que utiliza de maneira correta e responsável seus recursos, aproveita sua terra, respeita os direitos do trabalhador e explora a propriedade de maneira coerente, a fim de que gere desenvolvimento humano e também, de grande importância, a aclamada e buscada justiça social. É válido ainda um breve olhar sobre o primeiro inciso do artigo supracitado, que elenca como critério o "aproveitamento adequado" que pode ser entendido como produção. Logo, tal mandamento constitucional incentiva a produção de riqueza por parte do proprietário da terra, o que por sua vez é característica de um sistema capitalista, e olhando mais de perto, percebe então que tal compreensão não abarca ou se acopla a quaisquer ideologias políticas de cunho comunista como muitos leigos poderiam pensar.

A democracia, propriamente dita como Estado Democrático de Direito, deve compreender em seu sistema essencial a liberdade e a igualdade como objetos de suma importância.

Isso é notório, vez que o próprio pensamento clássico de Hans Kelsen (2000, p. 180) ressalta a importância da liberdade e da igualdade no sistema democrático, sendo que afere:

[...] a síntese de liberdade e igualdade, característica essencial da democracia, significa que o indivíduo, o ego, deseja liberdade não apenas para si mesmo, mas também para os outros, para o tu.

É importante tal explicação, pois os princípios da Constituição Federal de 1988 são referencial democrático, que prezam pelos valores de uma sociedade plural, livre, permeada de harmonia e igualdade entre seus sujeitos. Não é uma visão otimista, é apenas parte do que elege como objetivo de sua existência a própria Constituição.

Tendo em vista a importância do requisito da função social da propriedade do ponto de vista legal e constitucional, parte-se para uma análise de sua eficácia no mundo dos fatos, o que só pode ser entendido após a compreensão de tal princípio da maneira correta.

A desapropriação possui forma legal de execução, mas é necessário que fique claro que deve ser feita para fins de interesse social vez que assim atribui eficiência que, 
como se sabe, é princípio elencado na própria Constituição Federal em seu art. 37:

Art. 37. A administração pública direta e indireta de qualquer dos Poderes da União, dos Estados, do Distrito Federal e dos Municípios obedecerá aos princípios de legalidade, impessoalidade, moralidade, publicidade e eficiência e, também, ao seguinte [...]

É interessante observar que os incisos e parágrafos subsequentes do artigo supracitado se desenvolvem de maneira contínua à ideia geral elencada no caput, conforme demonstram os princípios estabelecidos, dentro eles o Princípio da Eficiência.

Assim, é possível atribuir eficiência ao fato de se desapropriar, dentro dos termos da lei, para fins de interesse social e reforma agrária, o que por sua vez denota o compromisso do Estado com o cumprimento das normas constitucionais.

Ao se tratar de tal compromisso, entende-se que o Estado se compromete a solucionar as problemáticas sociais existentes, e assim, buscar com foco a tão aclamada justiça social. Tanto se fala de tal justiça nas atmosferas acadêmicas que se faz necessário entender melhor o que vem a ser a justiça social, mas antes, é importante relembrar como a Constituição Federal de 1988 se manifesta a esse respeito:

Art.3․ Constituem objetivos fundamentais da República Federativa do Brasil:

I - Construir uma sociedade justa livre e solidária;

II - Garantir o desenvolvimento nacional;

III - erradicar a pobreza e a marginalização e reduzir as desigualdades sociais e regionais;

IV - promover o bem-estar de todos sem preconceito de origem, raça, sexo, cor, idade e quaisquer outra forma de destinação.

Frise-se tal dispositivo como bússola para os caminhos e decisões a serem tomados pelo Estado. Absolutamente autoexplicativo, cabe alguns comentários sobre cada inciso. No primeiro, mencionase uma "sociedade justa", referência a justiça social. No segundo, busca-se o desenvolvimento nacional, e de certa maneira, não há desenvolvimento em âmbito nacional em meio social injusto. No terceiro, muito importante atentar-se para "reduzir as desigualdades sociais", o que faz também clara referência a justiça social, e por fim "promover o bem-estar de todos", o que é impossível no meio social injusto, que faz com que apenas alguns privilegiados desfrutem do "bem-estar".
Assim, que fiquem claras as obrigações estatais de buscar meios e tomar caminhos que levem a sociedade até o ponto mais próximo possível da justiça social, e há de se convir que não há justiça social em sociedade desigual e injusta, os dois modelos sociais não podem simplesmente coexistir, sendo ou um ou outro. Logo, o Estado assim deve se posicionar, e para melhor se fixar a ideia da justiça social, esclarece Grau (1997, p. 245):

\begin{abstract}
"Justiça social", inicialmente, quer significar superação das injustiças na repartição, a nível pessoal, do produto econômico. Com o passar do tempo, contudo, passa a conotar cuidados, referidos à repartição do produto econômico, não apenas inspirados em razões micro, porém macroeconômicas: as correções na injustiça da repartição deixam de ser apenas uma imposição ética, passando a consubstanciar exigência de qualquer política econômica capitalista.
\end{abstract}

Muito corretamente se esclarece tal conceito e acertadamente se ajusta para o entendimento dos "fins de interesse social" ao qual se refere a Constituição Federal de 1988 quando elenca tal razão para a desapropriação dentro dos termos legais.

$E$ adentrando mais a fundo nas noções da desapropriação propriamente dita, não fugindo dos termos do interesse social e da reforma agrária, faz-se imprescindivel tomar alguns pontos para o devido esclarecimento.

Observados os termos já discutidos anteriormente no que toca ao art. 186, CF/88, que estabelece critérios para o cumprimento do requisito da função social da propriedade, é correto afirmar que uma vez que a propriedade rural não atenda aos requisitos legais ou descumpra algum dos incisos do supracitado artigo constitucional, deverá ser objeto de desapropriação, que para termos de esclarecimento, Maria Sylvia Zanella di Pietro (2002, p. 170) afere:

A desapropriação é o procedimento administrativo pelo qual o Poder Público ou seus delegados, mediante prévia declaração de necessidade pública, utilidade pública ou interesse social, impõe ao proprietário a perda de um bem, substituindo-o em seu patrimônio por justa indenização.

Sem prejuízo do que já foi exposto, e no sentido de complementar as ideias construídas até aqui acerca do tema da desapropriação por interesse social e fins de reforma agrária, é pontual destacar o que diz Cretella Júnior (1980) sobre o tema:

Em sentido genérico, desapropriação é o procedimento complexo de direito público, pelo qual a Administração, fundamentada na necessidade pública, na utilidade pública ou no 
interesse social, obriga o titular de bem, móvel ou imóvel, a desfazer-se desse bem, mediante justa indenização paga ao proprietário.

Assim, é de se notar que o funcionamento da desapropriação, como já falado, tem seus fundamentos, principalmente trazendo para o caso específico desta análise, a questão da supremacia do interesse social.

Assim os princípios direcionam o caminho, como o princípio da dignidade da pessoa humana, como o princípio da presunção de inocência e como também o princípio aqui estudado da devida função social. E desses norteadores jurídicos surge a regra, a norma positivada. Essa que se aplica para garantir aquilo que é pétreo, fundamental.

A regra infraconstitucional positivada é bem menos abrangente do que o Princípio, mas é também de extrema relevância. Ela deve ser permissiva ou proibitiva, fundada em determinados pressupostos, ou seja, ela autoriza ou ela proíbe (CANOTILHO, 1998, p. 1.177).

Muitas dúvidas persistem quando o tema é a desapropriação, não há surpresa, claro, vez que o tema é ignorado por grande parte da sociedade e é demasiado complexo para os leigos, mas é importante que fique claro a necessidade de tal instituto para a manutenção da ordem social e para a busca da justiça e da igualdade, que como já foi demonstrado, são princípios do Estado Democrático de Direito ora estabelecido e buscado conforme as orientações da Carta Magna de 1988.

Logo, percebe-se que o direito de propriedade, ou seja, o direito de ser proprietário está também atrelado ao cumprimento do princípio da devida função social da propriedade, e assim explana o doutrinador José Afonso da Silva (1999):

A função social se manifesta na própria configuração estrutural do direito de propriedade, pondo-se concretamente como elemento qualificante na predeterminação dos modos de aquisição, gozo e utilização dos bens.

A desapropriação está, em termos gerais, regulamentada no Decreto-Lei 3.365/41, que discorre de maneira natural sobre os mecanismos e regras do procedimento complexo de tal instituto. Tem como o sujeito ativo aquele que pode expropriar o bem, momento em que este passará a compor o patrimônio da agente expropriador, entretanto, esse não é o objetivo final, mas sim transferir então a um terceiro que possa dar a devida função social da propriedade, assim, promovendo a justiça social e efetivação do princípio constitucional.
Para isso, é necessário entender que existem duas formas de desapropriação, quais sejam a clássica, também conhecido como ordinária, e a especial, também chamada de extraordinária, e estão ambas dispostas no art. $5^{\circ}$ da CF/88 em seu inciso XXIV. Há também uma terceira forma de expropriação não expressa em lei, porém provém de entendimento jurisprudencial: a modalidade indireta.

\section{Do poder de polícia do estado, das atribuições do poder público, da desapropriação, do interesse social e reforma agrária}

Quando há a necessidade de se referir aos temas concernentes à desapropriação, como a propriedade, a posse, os princípios da Constituição Federal, a justiça social, a lei e ao indivíduo na sociedade, há também o que se dizer sobre um ponto especial do Instituto da Desapropriação, que é o Poder de Polícia do Estado.

Assim, rumam para esse tema as próximas linhas, sendo indispensável esclarecer alguns pontos primordiais de como o Estado exerce o poder de polícia dentro da desapropriação para fins de interesse social e reforma agrária, tendo sempre em vista os objetivos elencados pela Constituição Federal de 1988.

De certa forma, há uma definição clássica para função social, que é relevante se entender para uma melhor explanação quanto ao Poder de Polícia do Estado, para tanto, Leon Duguit (1911, apud, GOMES, 2007, p 126) afere:

A propriedade deixou de ser o direito subjetivo
do indivíduo e tende a se tornar a função social
do detentor da riqueza mobiliária e imobiliária;
a propriedade implica para todo detentor de
uma riqueza a obrigação de empregá-la para o
crescimento da riqueza social e para a
interdependência social. Só o proprietário pode
executar uma certa tarefa social. Só ele pode
aumentar a riqueza geral utilizando a sua
própria; a propriedade não é de modo algum
intangível e sagrado, mas um direito em
contínua mudança que se deve modelar sobre
as necessidades sociais às quais deve
responder.

Logo, há o entendimento de que os princípios coexistem, pois há um princípio que lhe dá o direito de ser dono e há outro princípio que lhe impõe o dever de aferir a função social ao bem de que é dono. E nos casos em que um ou mais princípios se enfrentam, é preciso que se considere o "valor" para buscar a solução (BONAVIDES, 1994, 251), diferentemente das normas positivadas e isso ocorre vez que o princípio é abstrato e 
possui uma abrangência dimensional infinitamente maior do que uma regra, que é debatida somente no sentido em que está escrita, e a esse mesmo sentido se restringe também sua validade.

Assim também, ao fato de se desapropriar vincula-se ao necessário uso do poder de polícia do Estado, que se faz presente cada vez mais nos atos do Poder Público, dado que Di Pietro Di Pietro (2003, p.120) afere:

O poder de polícia sofreu uma ampliação, não apenas de conteúdo, mas também de extensão, porque, enquanto originariamente somente justificava a imposição de obrigações de não fazer, passou, com o tempo, a impor obrigações de fazer, ou seja, a impor o dever de utilizar o bem. Neste momento é que se começou a falar em função social de propriedade.

É importante notar como se abre o assunto em tela a partir do ponto em que se percebe essa influência do poder do Estado, entretanto, uma influência, diga-se de passagem, vinculada aos anseios constitucionais de 1988.

Observa-se a importância de dar seguimento ao tema proposto, finalizando as considerações sobre o poder de polícia do Estado e seguindo para as considerações finais.

Vale também dizer que todo o processo de desapropriação é de extrema relevância social e jurídica, esse procedimento é uma forma de trazer dignidade à população, principalmente os mais vulneráveis, que são uma boa parcela do total, assim, buscando nada além da efetivação dos princípios da Constituição Federal de 1988 e a realização da sonhada justiça social, também buscada pela Carta mencionada.

Muito se fala sobre o tema, mas muitas pessoas hoje vivem em situações de extrema miséria, correndo risco de vida em lugares de alta periculosidade, beiras de rodovias, viadutos, pontes, como bem relatado por Strozake (2002, p. 13-17).

Cabe ao Estado, não só através das leis provenientes do Poder Legislativo, ou mesmo das políticas públicas do Poder Executivo, mas também através das demandas do Poder Judiciário. Como já foi discutido aqui, cabe também à Ciência Jurídica declinar sobre tais questões e buscar sua solução.

Claro que isso não seria nenhum tipo de apelo ao chamado "ativismo judicial", mas seria de certa forma, a simples tutela jurisdicional buscando atender os anseios da Constituição Federal de 1988.

Ainda tratando-se da desapropriação como uma ferramenta poderosa no combate às desigualdades e na busca da justiça social, sempre visando o interesse público e social, na luta pela efetivação do Princípio da devida Função Social da propriedade, é importante ressaltar o que esclarece a Lei Federal 8.629 de 1993, sob a égide dos preceitos constitucionais, sobre o tema:

Art. $2^{\circ} \mathrm{A}$ propriedade rural que não cumprir a função social prevista no art. 9० é passível de desapropriação, nos termos desta lei, respeitados os dispositivos constitucionais.

0 artigo supracitado, que dispõe sobre os termos da reforma agrária, que por sua vez é estabelecida na própria Constituição.

As questões que tangem a desapropriação e a devida função social da propriedade são tão enfáticas na sociedade que podem influenciar todos os setores, inclusive o setor econômico de um país. Buscar assim a desapropriação para fins de interesse social e reforma agrária pode melhorar a produção e a economia de um país, combatendo inclusive o êxodo rural, conforme explica Gursen (1989, p. 157):

\begin{abstract}
Quando existem aspectos econômicos e sociais em total desarmonia, dentro de uma mesma sociedade; quando o aspecto social é totalmente deficiente; quando o homem do campo não tem terra e/ou está concentrada em mãos de poucos, em prejuízo de grande número de homens sem-terra ou com terra insuficiente e não agricultável, se não houver uma reforma agrária para corrigir tais distorções, ocorrerá, como conseqüência destes fatos, o êxodo rural. O homem do campo, com sua família, irá para a cidade, em busca de uma vida supostamente melhor.
\end{abstract}

Assim, vale dizer que o Poder Público precisa criar as condições necessárias para que o trabalhador tenha acesso à terra, conforme estipula o Estatuto da Terra em seu art. $2^{\circ}, \S 2^{\circ}$, inclusive, se possível, na região onde habita:

Art. $2^{\circ}$ É assegurada a todos a oportunidade de acesso à propriedade da terra, condicionada pela sua função social, na forma prevista nesta Lei.

\section{$\S 2^{\circ}$ É dever do Poder Público:}

a) promover e criar as condições de acesso do trabalhador rural à propriedade da terra economicamente útil, de preferência nas regiões onde habita, ou, quando as circunstâncias regionais, o aconselhem em zonas previamente ajustadas na forma do disposto na regulamentação desta Lei;

b) zelar para que a propriedade da terra desempenhe sua função social, estimulando planos para a sua racional utilização, promovendo a justa remuneração e o acesso do trabalhador aos benefícios do aumento da produtividade e ao bem-estar coletivo. 
Vale dizer, também, que tudo que é dito no supracitado artigo se refere a uma obrigação atribuída ao Estado, através do Poder Público, sem prejuízo, claro, das demandas judiciais diante da inércia ou ineficácia da Administração Pública, nesse sentido, leciona Antonio Moura Borges (2006, p. 41):

Promover e criar as condições de acesso ao trabalhador rural à propriedade da terra economicamente útil, significa utilizar dos instrumentos da Reforma Agrária para adquirir a terra, como por exemplo, desapropriação por interesse social, aquisições, destinação de terras do domínio público e etc, para em seguida distribuilla através de projetos de assentamentos, concedendo-a em parcelas ao trabalhador rural denominado parceleiro dentre aqueles que se inscreveram para lograr a concessão.

Tanto se faz presente o impacto da Reforma Agrária, que, para cabal conclusão do raciocínio aqui construído, se faz imprescindível uma colocação acertada sobre o assunto, que não finaliza, claro, a densa argumentação, mas apenas reforça o que tem sido defendido desde os primórdios da presente Tese de Conclusão de Curso, para tanto, Taísa Dosso (2008, p. 84) pondera:

Como visto, a realização da reforma agrária é uma necessidade para o Brasil. Em razão da sua importância e, tendo em vista os reflexos que gera, é necessário que seja concretizada de forma a resolver efetivamente o problema da má distribuição de terras no país, bem como as conseqüências sociais daí decorrentes.

Um dos aspectos de observância obrigatória nesse processo é a conservação dos recursos ambientais, de maneira a possibilitar ao trabalhador rural não apenas o acesso à terra, mas também sua exploração contínua e sustentável.

Ou seja, para que atenda o objetivo proposto, a reforma agrária deve ser realizada de forma ambientalmente sustentável.

\section{CONSIDERAÇÕES FINAIS}

Diante de tudo que aqui foi exposto, comentado, debatido e estudado, cabe ainda ressaltar alguns pontos finais para uma conclusão adequada ao que se propõe o todo da pesquisa.

Como a desigualdade social incide de maneira alarmante no Brasil, as injustiças sociais são recorrentes, e a prova disso é a própria constituição que impõe tais objetivos a serem buscados e, também alcançados, é necessário se falar sobre a reforma agrária. É necessário buscar meios de solucionar tais intempéries através do direito.

Claro que outras áreas também se dedicam na busca incansável pelas soluções mais adequadas e cabíveis para este momento atual, seja a filosofia, seja a sociologia, sejam as ciências sociais, seja a psicologia ou a pedagogia, ou ainda qualquer área que busque compreender o indivíduo, a sociedade e como tudo se une no que se conhecer por meio social.

0 direito tem aplicação direta em tal meio, altera as relações e impacta a vida dos indivíduos sobremaneira, seja através da elaboração de leis, normas e regras, quer seja através da aplicação dessas leis, normas e regras, e isso é essencial para a construção da sociedade buscada na lei maior, a Constituição da República Federativa do Brasil de 1988, que é o norte de toda e qualquer legislação que se faça existir ou que venha a ser criada a posteriori.

Assim, conclui-se que as problemáticas sociais são problemas para que o Direito se incline, entenda, pondere e solucione de maneira justa, sempre de acordo com os Princípios da Constituição Federal e do Estado Democrático de Direito.

Há de se convir que a desigualdade é um grande problema que assola o país, talvez um dos principais causadores de criminalidade, êxodos, violência, desunião e revolta. Como já foi dito nesta pesquisa, os próprios anseios elencados na Constituição comprovam a existência de tal fato, de outro modo não existiria o texto dos Art. $3^{\circ}$, art. $5^{\circ}$, art. $7^{\circ}$ e vários outros dispositivos constitucionais.

Há também que se enfatizar ainda que a desapropriação para fins de interesse social e de reforma agrária é um artifício significativo para que se busque e que se encontre a sociedade sonhada pela Constituição Federal de 1988.

De modo que assim, o direito se direciona para a criação da sociedade justa e permeada de igualdade e bemestar, conforme estabelece a Carta Magna. Dado que a desigualdade social e as injustiças encarnam o terrível espírito do caos e do medo.

Os princípios constitucionais então ganham perspectiva de aplicação como transformadores, vez que marcam o tempo. Por exemplo, se no passado houve tortura, a constituição agora proíbe tal conduta. Se no passado houve racismo, a constituição agora o proíbe. Não que já não exista mais o racismo nas veias urbanas sociais, mas se apresenta de maneira velada, clandestina e disfarçada.

Assim, através da norma positivada, que nasce norteada pelo Princípio Constitucional, que busca solucionar os problemas sociais existentes, se aplica para gerar efeitos. 
Diante de todo o exposto, conclui-se que a sociedade mudou seus conceitos de propriedade ao longo da história, suas ideias de posse, as teorias criadas para dar amparo jurídico e também social, e atualmente, sobremaneira, se preza não somente por ser dono, ou por possuir o desejo de o ser, o animus domini, mas também pelo dever que o dono possui de dar função ao seu bem, de proporcionar função social em sua propriedade, o que por sinal, é benéfico sobremaneira para o próprio dono, que terá maior produção e possivelmente maiores lucros.

É importante também considerar que a ferramenta da desapropriação para os fins de interesse social e reforma agrária, dentro das estipulações legais, é indispensável para que se solucione a problemática social e para que se alcance a sociedade buscada pela Constituição Federal de 1988, justa, igualitária e pacífica.

Não obstante, a sociedade atual se transforma, as leis se modificam também ao passo em que a mentalidade das pessoas se altera, novas visões são buscadas e os horizontes são ampliados. O direito, como ciência que é, também sofre tais mutações, se aperfeiçoa e se adéqua aos tempos em que é vigente.

Nestas considerações finais, espera-se ter alcançado o satisfatório resultado de esclarecer as dúvidas fundamentais sobre o tema, sobre a expropriação e sobre os princípios Constitucionais, para tanto, estimase que a compreensão sobre o tema tenha transcendido os espaços de pensamento políticos e provenientes do senso comum e criado uma atmosfera adequada para o entendimento do assunto em proporções infinitamente mais amplas, dimensões que abrangem os aspectos essencialmente econômicos, sociais e, sobretudo no que toca às arestas jurídicas, não restando dúvida de que o ponto central da pesquisa e do estudo dessa tese se guiou pelos aspectos meramente jurídicos que the são peculiares, sanando assim os mal entendidos.

Fazendo saber também, que se conclui ainda da fundamentalidade dos esforços provenientes do Poder Público frente à árdua tarefa de combater as desigualdades e alcançar a justiça social, fazendo, dentro dos termos da lei, a desapropriação para fins de interesse social e reforma agrária.

\section{REFERÊNCIAS}

BANDEIRA DE MELLO, C. A. Curso de Direito

Administrativo, 9. ed. São Paulo: Malheiros, 1997.

BONAVIDES, P. Curso de direito constitucional. 5. ed. São Paulo: Malheiros, 1994.

BORGES, A. M. Curso Completo de Direito Agrário. Leme: EDIJUR, 2006.
BRASIL, Constituição da República Federativa do Brasil de 1988. 38. ed. São Paulo: Saraiva, 2000.

.Lei n 4.504 de 30 de Novembro de 1964. Disponível em:

<http://www.planalto.gov.br/ccivil_03/leis//4504.htm >. Acesso em: 11 jun 2019.

.Lei no 8.629, de 25 de Fevereiro de 1993.

Disponível em:

<http://www.planalto.gov.br/ccivil_03/leis/l8629.htm $>$. Acesso em: 12jun2019.

CANOTILHO, J. J. G. Direito constitucional e teoria da Constituição. 3. ed. Coimbra: Almedina, 1998.

CRETELLA JÚNIOR, J. Tratado geral da desapropriação. Rio de Janeiro:Forense, 1980.

DINIZ, M. H. Código Civil anotado / Maria Helena Diniz - 14. ed. rev. e atual. - São Paulo: Saraiva, 2009.

DI PIETRO, M. S. Z. Direito Administrativo. $14^{a}$ ed. São Paulo: Atlas, 2002.

. Direito Administrativo. 19 Ed. São Paulo: Atlas, 2008.

DOSSO, T. C. Reforma Agrária e Desenvolvimento Sustentável: aspectos obrigacionais e instrumentos legais de proteção. 135f.2008.Dissertação (Mestrado) Universidade Estadual Paulista Júlio Mesquita, Franca, 2008.

GOMES, O. Direitos Reais. Rio de Janeiro: Forense, 2007.

GRAU, E. R. A ordem econômica na Constituição de 1988. São Paulo: Malheiros Editores, 1997.

KELSEN, H. A Democracia. Tradução de Ivone Castilho Benedetti, Jefferson Luiz Camargo, Marcelo Brandão Cipolla e Vera Barkow. São Paulo: Martins Fontes, 2000.

MARX, K.; ENGELS, F. Manifesto do Partido

Comunista. 9. ed. Petrópolis, RJ: Vozes, 1999.

MIRANDA, A. G. de. Teoria de Direito Agrário. Belém: CEJUP, 1989.

SILVA, J. A. da. Curso de Direito Constitucional Positivo. 16. ed. São Paulo: Malheiros, 1999.

STROZAKE, J. J. (org.). Questões Agrárias: julgados comentados e pareceres. São Paulo: Método, 2002.

VENOSA, S. de S. Direitos Reais. São Paulo: Atlas, 2008. 